\title{
Solidizmo doktrina ir neurologija Vilniuje XIX amžiaus pirmojoje pusẻje
}

\begin{abstract}
E. Sakalauskaitė-Juodeikienė Santrauka. Medicinos literatūroje XVIII a. pirmojoje pusèje atsiradus ir ịsitvirtinus tokiems terminams kaip „skaidula“, „pluoštas“, „membrana“, ,tinklas“, ,audinys“, „vibracija“, „tonusas“, ,ịtampa“, humoralinè teorija pamažu užleido vietą kitai, pažangesnei - solidizmo doktrinai, pabrěžusiai ne skysčių, bet skaidulų ir pluoštų svarbą organizmo sandarai ir funkcijoms. Šio darbo tikslas - ištirti, kaip solidizmo doktrinos principai buvo taikomi Vilniaus imperatoriškojo universiteto klinikose, diagnozuojant nervų sistemos ligas. Išnagrinẻjus lotynų kalba parengtas ir Vilniaus universitete apgintas medicinos daktaro disertacijas, paaiškèjo, kad solidizmo doktrina Vilniuje buvo pripažịstama ir šios sistemos principais (ligos priežasčių derètų ieškoti vidaus organuose, o ne organizmo skysčiuose) buvo remiamasi, atliekant nervų ligomis sirgusių ligonių autopsijas ir klinikinę diagnozę patvirtinant post mortem.
\end{abstract}

Raktažodžiai: solidizmas, autopsija, nervų ligos, Vilniaus universitetas, Vilniaus klinikos.

\section{IVADAS}

Vakarų Europos medicinoje nuo Antikos laikų vyravo humoralinė doktrina, kurios pasekejjams liga buvo ne vieno organo ar organų sistemos pažeidimas, o viso kūno patologija, sukelta keturių organizmo skysčiu (kraujo, flegmos, juodosios ir geltonosios tulžies) pusiausvyros sutrikimo [1]. Žmogaus temperamentai taip pat sieti su organizmo skysčiu pusiausvyros sutrikimu: manyta, kad geltonosios tulžies perteklius būdingas cholerikui, juodosios tulžies melancholikui, kraujo - sangvinikui, gleivių - flegmatikui [2]. Norint padèti ligoniui pasveikti, reikia pašalinti ši organizmo skysčių pusiausvyros sutrikimą, skatinant ligą sukeliančių skysčių sekreciją, ekskreciją ar kraujavimą [3].

Frydrichas Hofmanas (Friedrich Hoffmann; 1660-1742), vokiečių kilmès gydytojas ir chemikas, Halès universiteto medicinos ir gamtos mokslų profesorius, knygoje Fundamenta medicinae („Medicinos pagrindai“, $1695 \mathrm{~m}$.) jau XVII a. pabaigoje teigè, kad svarbiausia orga-

\author{
Adresas: \\ Eglè Sakalauskaitè-Juodeikienè \\ Vilniaus universiteto ligonines Santaros kliniku \\ Neurologijos centras \\ Santariškiu g. 2, LT-08661 Vilnius \\ El.paštas egle.sakalauskaite-juodeikiene2@santa.lt
}

nizmo statybinė medžiaga yra skaidula; siūlai, plaušeliai ir gijos sudaro žmogaus kūno dalis ir organus [4]. Medicinos literatūroje XVIII a. pirmojoje pusèje atsiradus ir ịsitvirtinus tokiems terminams kaip „skaidula“, „pluoštas“, „membrana“, „tinklas“, „audinys“, „vibracija“, „tonusas“, „ịtampa“, humoralinė teorija pamažu užleido vietą kitai, pažangesnei - solidizmo (lot. solidus - tankus, kietas, tvirtas) - doktrinai, pabrèžusiai ne skysčių, bet skaidulu ir pluoštų svarbą organizmo sandarai ir funkcijoms [5].

Itakingas solidizmo sistemos ir jatromechanikos (gr. iatros - gydytojas, mechanica - mechanika) atstovas olandu gydytojas, chemikas ir botanikas Hermanas Burhavè (Herman Boerhaave; 1668-1738) ligas skirstè i dvi grupes: vienos pasireikšdavo dèl laisvų ir suglebusių, kitos - dèl sukietėjusių ir pernelyg stangrių skaidulų [4]. Pavyzdžiui, hipochondrija ir isterija sieta ne su skysčių pusiausvyros sutrikimu, o su skaidulų, kurios tapdavo laisvos ir suglebusios, patologija. Solidizmo doktrinos pasekejjai teigè, kad cirkuliuojantys skysčiai yra tarsi gyvybinès sultys, svarbios skaidulų mitybai ir atsinaujinimui [5].

Kitas solidistas, italų anatomas Džiovanis Batista Morganjis (Giovanni Battista Morgagni; 1682-1771) knygoje De sedibus et causis morborum („Apie ligų vietas ir priežastis”, $1761 \mathrm{~m}$.) patvirtino, kad apopleksiją sukelia ne organizmo skysčių pusiausvyros sutrikimas, o kraujo arba serozinio skysčio išsiliejimas ir smegenų substancijos su-

(C) Neurologijos seminarai, 2019. Open Access. This article is distributed under the terms of the Creative Commons Attribution 4.0 International License CC-BY 4.0 (http://creativecommons.org/licenses/by/4.0/), which permits unrestricted use, distribution, and reproduction in any medium, provided you give appropriate credit to the original author(s) and the source, provide a link to the Creative Commons license, and indicate if changes were made. 
spaudimas. Dž. B. Morganjis, atlikdamas mirusių ligonių autopsijas, patvirtino savo mokytojo Antonijaus Marijos Valsalvos (Antonio Maria Valsalva; 1666-1723) pastebėjimą, kad vienos kūno pusès galūnių paralyžiaus priežastis yra priešingos pusės intracerebrinė hemoragija, ir ši fenomeną pavadino Valsalvos doktrina [6]. Nors Dž. B. Morganjis buvo solidistas, pagrindiniu apopleksijos gydymo metodu vis dèlto laikè kraujo nuleidimą ir rekomendavo ligoniui atlikti jungo venos flebotomiją (tikèta, kad kraujas iš galvos smegenų pasišalins greičiau, ịpjovus iš smegenų išeinančią veną).

Solidistai tvirtino, kad fizinis aktyvumas sustiprina suglebusias skaidulas, padidina jų susitraukimo jègą, tačiau nesaikingas kūno varginimas gali jas išsausinti ir sukietinti. Teigta, kad šaltas ir sausas oras skaidulas sustingdo ir sukietina, karštas ir drėgnas - atpalaiduoja ir sumažina skaidulų elastingumą, todèl gyvybinès sultys užsistovi ir sugleivèja. Pabrèžta dietos svarba: aštrūs, aitrūs patiekalai padidina skaidulų virpẻjimą, mineraliniai vandenys pagerina jų tonusą. Kita vertus, net ir solidizmo doktrinos pasekejjai savo ligoniams skyrẻ kraujo nuleidimus, dėlių terapiją, emetikus, vidurius laisvinamuosius ir kitus antiflogistinio (priešuždegiminio) gydymo metodus. Pavyzdžiui, H. Burhavė, gydydamas ligonius, sirgusius pneumonija, rekomenduodavo „skubiai atlikti kraujo nuleidimą, ir gausiais kiekiais" [7].

Kiek vèliau, XVIII a. pabaigoje, pabrėžta skaidulų, susijusių su centrine ir periferine nervų sistema, t. y. nervų, svarba organizmo funkcijoms reguliuoti [8]. XVIII a. viduryje jatromechaninị požiūrị ị kūną (kūnas - tarsi hidraulinė mašina, kurios vamzdžiais srūva gyvybiniai skysčiai) pakeis vitalistinè koncepcija (kūnas - nervinių struktūru reguliuojamas, jaučiantis ir dirglus organizmas) [5].

Šio darbo tikslas - išsiaiškinti, kaip solidizmo doktrinos principai buvo taikomi Vilniaus klinikose, diagnozuojant nervų sistemos (NS) ligas.

\section{MEDŽIAGA IR METODAI}

Darbo šaltiniai - lotynų kalba parengtos Vilniaus imperatoriškojo universiteto (1803-1832 m.) medicinos daktaro disertacijos. Nors visose disertacijose galime rasti solidizmo doktrinos apraiškų, iš 26 nervų ligų klausimus nagrinèjusių mokslinių darbų šiam tyrimui atrinkti keturi: lietuvio Vincento Vladislovo Herberskio (Vincentius Vladislaus Herberski; 1784-1826) „Medicininė praktinė inauguracinè disertacija apie stuburo kanalo vandenę" (Dissertatio inauguralis medico - practica de hydrope specus vertebralis, 1812 m.), žemaičio, Medicinos instituto auklètinio Jono Dirvianskio (Joannes Dyrwiański) „Inauguracinė disertacija, pristatanti hidrofobijos istoriją“ (Dissertatio inauguralis historiam hydrophobiae exhibens, $1815 \mathrm{~m}$.), Andriaus Godžembos (Andreas Godziemba) iš Varšuvos „Inauguracinis tyrimas, nagrinejantis tifo ir encefalito diagnozę" (Tentamen inaugurale diagnosim typhi et encephalitidis sistens, $1816 \mathrm{~m}$.) ir Vilniaus gydytojo lietuvio Ferdinando Guto (Ferdynand Gutt; 1790-1871) „Medici-

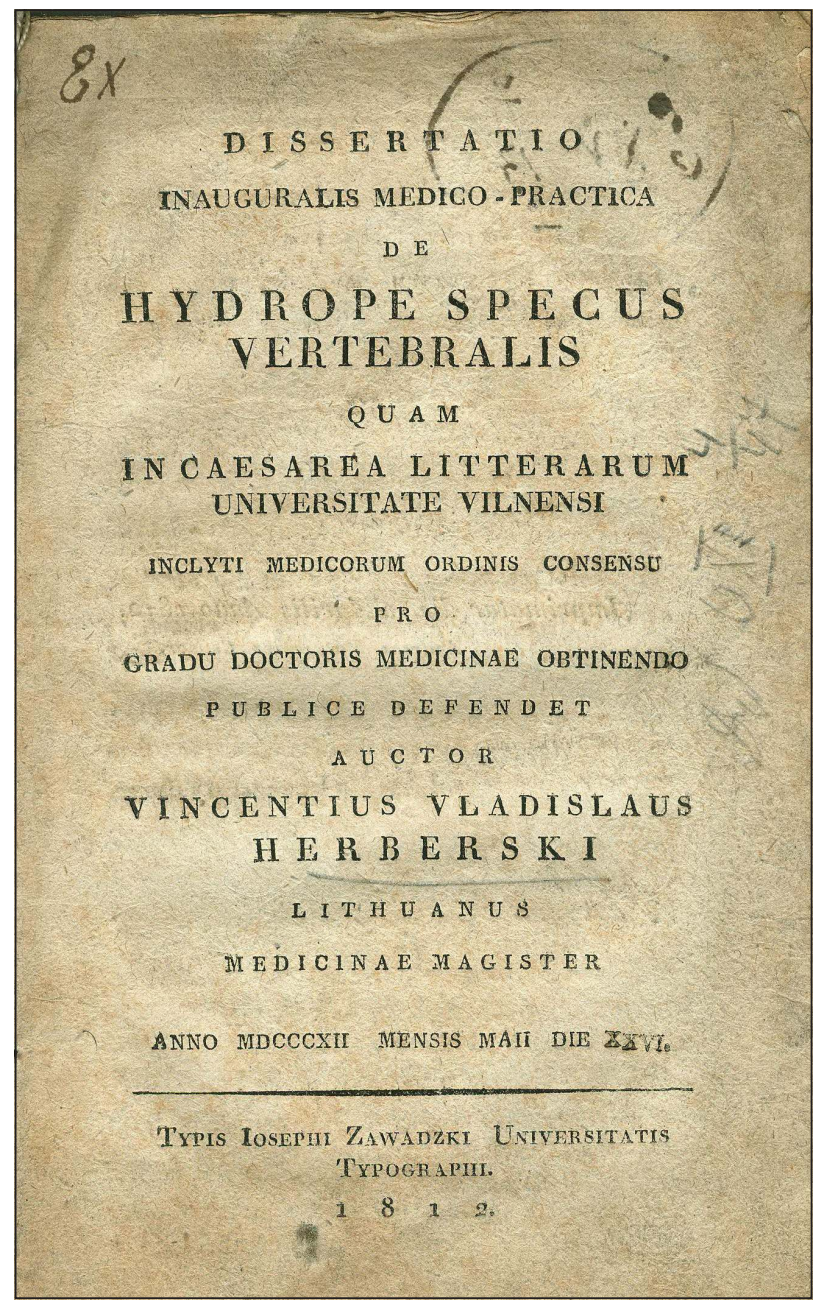

1 pav. V. V. Herberskio disertacijos Dissertatio inauguralis medico - practica de hydrope specus vertebralis (Vilnius, $1812 \mathrm{~m}$.) titulinis lapas.

Vilniaus universiteto biblioteka (su leidimu).

ninė praktinė inauguracinė disertacija apie įvairias stuburo ligas“" (Dissertatio inauguralis medico - practica analecta de morbis columnae vertebralis exhibens, $1823 \mathrm{~m}$.). Naudoti kokybiniai tyrimo metodai - šaltinių analizès, sintezès ir lyginamasis metodai.

\section{REZULTATAI}

Vilniaus imperatoriškojo universiteto (VU) auklètinis lietuvis Vincentas Vladislovas Herberskis $1812 \mathrm{~m}$. apgintoje „Medicininèje praktinèje inauguracinejje disertacijoje apie stuburo kanalo vandenę" (1 pav.) aprašè VU anatomijos profesoriaus Jono Lobenveino (Johannes Andreas Loebenwein; 1758-1820) pristatytą naujagimio spina bifida atveji:

„Žydè moteris, $25 \mathrm{~m}$. amžiaus, <..> vidutinio ūgio, liekno kūno sudèjimo, sveika ir ištekẻjusi už sveiko vyro, trijų vaikų motina, kuriai kartais patindavo kaklo ir pažandinės liaukos, 4-ą néštumo mẻnesị stipriai išgąsdinta, pajuto dideli nuovargi $<\ldots>$ ir paskutinèmis nėštumo dienomis - susilpnèjusius vaisiaus judesius. $1810 \mathrm{~m}$. lapkričio 
11 d. pagimdẻ kūdikị be matomų lyties organų, be išangès, kirkšnyse stebèti atsivèrę šlapimtakiai <...>, kryžkaulio srityje stebėtas žąsies kiaušinio dydžio tumoras, minkštas, elastingas, fliuktuojantis, neskausmingas, beveik nemažèjantis suspaudus, be odos spalvos pokyčių. Kūdikio apatinès galūnės buvo paralyžiuotos, jis vangiai žindè krūtị, nyko, [ir galiausiai] mirè.“ [9]

Atlikta kūdikio autopsija: galvos smegenys ir smegenėlès - be patologijos, skilveliai - laisvi, neišsipūtę, smegenų skystis perėjo ị kryžmens srities tumorą. Suskaičiuoti 23 slanksteliai, iš jų keturi - juosmeniniai. Krūtininès ir juosmeninès dalies slanksteliai buvo pakrypę i kairę pusę, jų keterinès ataugos - be matomos patologijos. Rastas plyšys trijuose kryžmeniniuose slanksteliuose, per kurị ir išsiveržè tumoras, sudarytas iš nugaros smegenų, cauda equina ir nugaros smegenų skysčio [9].

Žemaitis Jonas Dirvianskis 1815 m. apgintoje „Inauguracinejje disertacijoje, pristatančioje hidrofobijos istoriją" pateikè $15 \mathrm{~m}$. amžiaus mergaitės, $1811 \mathrm{~m}$. lapkriti gydytos VU Terapijos klinikoje, ligos istoriją. Ligonè pajuto skausmą nugaroje tarp menčių, vėliau pasireiškẻ konvulsijos, viso kūno opistotonusas, tetaninis galūnių sustingimas ir galiausiai, kaip manė autorius, patognominis ligos simptomas - hidrofobija. Mirus ligonei, atlikta nugaros smegenų sekcija: „nuo pirmo kaklinio iki ketvirtojo krūtininio [slankstelio] stebėtas nugaros smegenų uždegimas, kairiau - susikaupęs kraujingas ekstravazatas" [10].

VU auklètinis Andrius Godžemba $1812 \mathrm{~m}$. išleistoje disertacijoje „Inauguracinis tyrimas, nagrinėjantis tifo ir encefalito diagnozę" pateikè tifo ir encefalito diferencinę diagnostiką, remdamasis ne tik ligos simptomais, eiga, bet ir autopsijos duomenimis. Autorius pabrèžè, kad, mirus ligoniui, „skrodimas yra reikalingas diagnozès patvirtinimui ir mokslo pažangai“" [11]. Jei ligonis sirgo tifu ar kita karštine, autopsija įneša nedaug aiškumo: odos paviršius būna nusètas mėlynomis dėmėmis, pilvas - kietas, išpūstas, kaukolès ertmèje randamas serozinis, kraujingas ar supūliavęs ekstravazatas, panašūs pakitimai nustatomi krūtinės ir pilvo ertmėse. Jei miręs ligonis sirgo encefalitu, post mortem būna nustatoma išskirtinai smegenų patologija: kietasis ir švelnusis dangalas būna sustorèjęs, priaugęs prie kaukolès, smegenyse ar smegenèlių substancijoje, pailgosiose smegenyse nustatomas uždegimas, kraujagyslès būna pritvinkusios kraujo, kartais smegenys būna kietos ir sausos arba suminkštèjusios dèl pūlinių, varškinių masių, arba paveiktos gangrenos (sphacelo). Nugaros smegenyse „pūliniai ir gangrena kartais net slankstelius pragraužia“ [11].

Kitas medicinos mokslų daktaras lietuvis Ferdinandas Gutas $1823 \mathrm{~m}$. apgintos „Medicininės praktinès inauguracinès disertacijos apie ịvairias stuburo ligas" skyrelyje apie galūnių ir sekinančias ligas (morbos extremitatum et tabificos) aprašè kaltūnu sirgusị ligonị: „Vyras, baigiantis 38-tus gyvenimo metus, kilęs iš kaltūnuotos giminès, nuo vaikystès sirgęs blauzdų votimis ir viso kūno silpnumu, nuo $15 \mathrm{~m}$. apimtas šašų su niežuliu (psora), visiškai pasiligojo, [jam net] 1819 m. rugsẻjo mèn. sukarščiavus, atėmé kojas.“ [12]. 1820 m. rugsejjị ligonis gydytas VU Chirurgi-

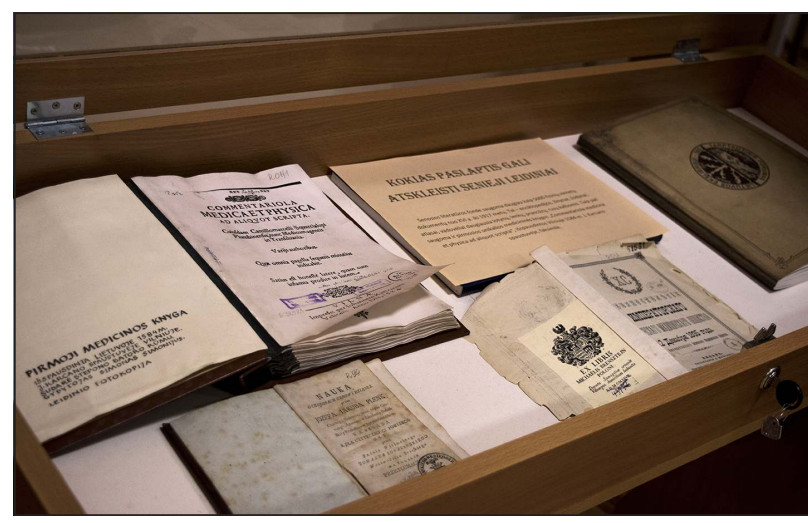

2 pav. Senujų leidinių ekspozicija Lietuvos medicinos bibliotekoje, tarp kurių - ir S. Simonijaus Commentariola medica et physica ad aliquot scripta (Vilnius, $1584 \mathrm{~m}$.) fotokopija.

Eglès Sakalauskaitès-Juodeikienės nuotr.

jos klinikoje. Sergančiojo stuburas išoriškai buvo normalus, kojos - liesos, sustingusios, pilvo raumenys - atsipalaidavę. Ligoniui skirti prideginimai stuburo šonuose, dèl šlapinimosi sutrikimo ịvestas kateteris. Nepaisant gydymo, ligonio būklè blogejo: pradèjo viduriuoti, alsavimas tapo sunkus, galūnès - šaltos, marmuruotos, išryškejjo $f a$ cies hippocratica. Ligoniui mirus, atlikta autopsija ir rastas „pusės lazdyno riešuto dydžio auglys ties L4-L5 kremzle, kuris buvo išsiveržęs į nugaros smegenų pusę. Naviko kapsulè buvo tvirta, užpildyta balkšvu skysčiu“" [12]. Jokių uždegimo požymių nestebėta, vidaus organai, „rūpestingai apžiūrèti“", - visiškai sveiki. Patvirtinta klinikinė diagnozė: ligos priežastis - tumoras ir lètinis uždegimas, kurị sukèlè kaltūnas.

F. Gutas, aptardamas šią ir kitas aprašytas ligas, padarė išvadą, kad stuburo skausmų (rachialgijos) priežastys gali būti įvairios - sausgyslių, raiščių, slankstelių pažeidimai ir uždegimai. Pažeidus stuburą, dirginami iš jo išeinantys nervai, kurie reguliuoja šlapimo pūslès, žarnų funkcijas ir kojų raumenų jėgą. Galbūt ne visiškai tiksliai, tačiau autorius bandè atskirti krūtininès ir juosmeninès nugaros smegenų dalies patologiją, tvirtindamas, kad, ,jei pažeidžiami krūtininiai slanksteliai, labiausiai nukenčia kojos ir genitalijos, jei juosmeniniai - šlapimo pūslès ir tiesiosios žarnos veikla" [12].

\section{APTARIMAS}

Solidizmo užuomazgomis Lietuvos Didžiojoje Kunigaikštystejje (LDK) galètume laikyti gydytojų Simono Simonijaus (Simone Simoni; 1532-1602) ir Mikalojaus Bučelos (Niccolo Buccella; 1520-1599) atliktą mirusio Lenkijos karaliaus ir Lietuvos didžiojo kunigaikščio Stepono Batoro (Stefan Batory; 1533-1586) skrodimą, siekiant išsiaiškinti jo mirties priežastis [13]. Manoma, kad tai - veikiausiai pirmoji atlikta autopsija LDK. Dėl skirtingai diagnozuotos S. Batoro ligos M. Bučela susipyko su S. Simonijumi: M. Bučela manė, kad karalius sirgo astma, o S. Simonijus teigè, kad valdovui - epilepsija. Vienas kito nemėge 
medikai prie valdovo buvo paskutinėmis jo gyvenimo akimirkomis ir siūlè skirtingus gydymo metodus [14]. Italų gydytojas S. Simonijus taip pat yra pirmojo LDK spausdinto medicinos mokslinio veikalo Commentariola medica et physica ad aliquot scripta (,Medicinos ir gamtamoksliniai komentarai apie tai, kas parašyta“), išleisto 1584 m. Vilniuje, J. Karcano spaustuvejje, autorius [15] (2 pav.).

VU Terapijos, Chirurgijos ir Akušerijos klinikose XIX a. pr. stengtasi visiems gydytiems ir mirusiems ligoniams atlikti autopsijas. Profesorius tevvas Johanas Peteris Frankas (Johann Peter Frank; 1745-1821), su kuriuo jo sūnus Jozefas Frankas (Joseph Frank; 1771-1842) 1796-1802 m. dirbo bendrojoje Vienos ligoninèje, minètoje gydymo ịstaigoje padidino autopsijų skaičių, skatindamas po mirties ištirti ligonius, sirgusius retomis arba nepagydomomis ligomis, taip pat tais atvejais, kai diagnozė gydytojui buvo neaiški. J. P. Frankas Vienoje įkūrè ir patologijos muziejų [16]. Ši klinikinį anatominị metodą tėvas ir sūnus Frankai atsivežè ị Vilnių ir naudojo Vilniaus klinikose praktiškai. İspūdinga tai, kad ir Frankai su studentais, ir kiti Vilniaus gydytojai post mortem tyrè ne tik galvos, bet ir nugaros smegenis. Tuo metu Šarlis Prosperas Olivjè d'Anži (Charles Prosper Ollivier d'Angers; 1796-1845) $1824 \mathrm{~m}$. išleistame Maladies de la moelle epiniére („Traktate apie nugaros smegenų ligas") kritikavo savo amžininkus, autopsijose per mažai dėmesio skirdavusius nugaros smegenims [17]. Taigi Vilniuje XIX a. pr. jau buvo pradètas taikyti klinikinis anatominis metodas, kurị tik XIX a. antrojoje pusejje Paryžiaus Salpêtrière ligoninėje galutinai ištobulins neurologijos profesorius Žanas Martinas Šarko (Jean-Martin Charcot; 1825-1893).

Kokiomis sąlygomis buvo atliekamos mirusių ligonių autopsijos XIX a. pr. Vilniuje, kai prozektoriai neturejo nei šaldymo įrenginių, nei kokybiškų ir nebrangių organus bei audinius fiksuojančių tirpalų? Žmogaus kaulai, apdoroti termiškai, gali išlikti nesudūlèję neribotą laiką, raumenys ir kraujagyslès žemesnèje temperatūroje suyra per kelias savaites, krūtinès ir pilvo ertmès organai - per kelias dienas, o galvos ir nugaros smegenys be fiksacijos suskystejja greičiausiai - per kelias valandas [18]. Sąlygos kokybiškoms autopsijoms ypač pablogėdavo šiltuoju metų laiku. Vadinasi, norėdami aptikti NS patologiją, prozektoriai turédavo imtis darbo nedelsiant, vos tik mirus ligoniui. Vargu ar kiekvieną autopsijose aprašytą encefalomaliaciją, serozinio skysčio susikaupimą galvos ir nugaros smegenyse galime laikyti tikrais patologiniais, o ne pomirtiniais pakitimais. Tačiau svarbiausia yra pats ketinimas: Vilniuje, kaip ir daugelyje Vakarų Europos klinikų, ligos priežasčiu pirmiausia ieškota vidaus organuose. Kita vertus, dažniausi ligonių autopsijų ir makroskopinių tyrimų radiniai buvo kraujo priplūdimai galvos ir nugaros smegenyse, kurie tik patvirtino humoralinę, uždegiminę NS ligų patogenezès teoriją. Andriejus Sniadeckis (Jędrzej Śniadecki, Andrzej Śniadecki; 1768-1838) veikale Teorya jestestw organicznych („Organinių būtybių teorija“, 1804, 1811, 1838 m.) taip apibūdino dvi dideles ir garsias humoristų ir solidistų patologines sistemas: „Mat, kaip vadinamieji humoristai $<\ldots>$ žmoguje nematė nieko, tik indus ir [skysčių] tekèjimus, taip, iš kitos pusès, solidistai <...>, ypač šlovingojo Brauno sekta, nieko nematè, tik nervus.“ $[19,20]$

Medicinos daktaras V. V. Herberskis, autopsijos metu radęs plyšį trijuose kryžmeniniuose slanksteliuose, per kurị išsiveržè tumoras, sudarytas iš nugaros smegenų, cauda equina ir nugaros smegenų skysčio, patikslino naujagimio auglio morfologiją, remdamasis ne humoraline, o solidizmo doktrina. Veikiausiai kūdikio spina bifida etiologiniu veiksniu laikytas motinos išgąstis nèštumo metu. Nuo XVIa. medicinos literatūroje imaginatio gravidarum (nèščiųjų įsivaizdavimas) ir išgąstis vertintas kaip viena iš igimtų vaisiaus malformacijų priežasčių: manyta, kad egzistuoja tiesioginis ryšys tarp motinos ir vaisiaus nervų, teigta, kad sujaudinta motinos spiritus animalis (gyvybinė dvasia) per bambagyslę pereina vaisiui, pažeisdama minkštas ir jautrias negimusio kūdikio skaidulas [21].

J. Dirvianskio pristatytas hidrofobijos atvejis kelia abejonių: mirusios mergaitès autopsija parodè nugaros smegenų uždegimą (mielitą) ir kraujavimą ị stuburo kanalą. Kita vertus, hidrofobija XIX a. pr. buvo vadintas ir mirtinas nervinis susirgimas, pasireiškiantis įkandus pasiutusiam gyvūnui, ir savaime, be gyvūno ịkandimo pasireiškianti liga, kai prineštas prie ligonio gèrimas sukeldavo skausmingą ryklès ir krūtinès ląstos susitraukimą, baimę, sergantysis jausdavo nepakeliamą karščio jausmą ir nepasotinamą troškulị [22]. Tik dalyje VU disertacijų, skirtų hidrofobijai nagrinėti, paminètas pasiutusio gyvūno ịkandimas, tačiau pasiutligès viruso Rhabdoviridae infekcija tuo metu nebuvo nustatoma (virusologinė ligos etiologija ir Negri kūneliai CNS atpažinti tik nuo 1903 m.), tad dalis aprašytų hidrofobijos atvejų galètų būti priskiriama kitos kilmès mielitams ar meningoencefalitams.

A. Godžembos pasiūlyta tifo ir encefalito diferencinė diagnostika yra išskirtinai tiksli: sergant encefalitu, post mortem pakitimai randami galvos smegenyse ir jų dangaluose, kai tifas - sisteminè viso organizmo liga.

F. Gutas disertacijoje bandè atskirti krūtininès ir juosmeninès nugaros smegenų dalių patologiją, tvirtindamas, kad, jei pažeidžiami krūtininiai slanksteliai, labiausiai nukenčia kojos ir genitalijos, jei juosmeniniai - šlapimo pūslès ir tiesiosios žarnos veikla. Šiandien žinoma, kad, perpjovus stuburo krūtininės dalies nugaros smegenis, trinka kvėpavimas, pasireiškia spastinė kojų paraplegija, anestezija žemiau pažeidimo segmento, susilaiko šlapimas ir išmatos. Pažeidus juosmeninị sustorèjimą (intumescentia lumbalis), taip pat pasireiškia kojų paraplegija, tačiau ji yra vangi, nustatoma anestezija, susilaiko šlapimas ir išmatos [23].

VU Chirurgijos klinikoje gydyto $38 \mathrm{~m}$. amžiaus kaltūnuoto vyro, kuriam „atėme““ kojas ir susilaikè šlapimas, post mortem tyrime rastas auglys ties L4-L5 kremzle galèjo būti ir masyvi tarpslankstelinio disko išvarža, ir perineurinè cista ar kita organinė patologija, sukèlusi nervinių šaknelių kompresiją. Tačiau F. Gutas, nors ir pademonstravęs pažeidimo morfologinę priežastị, svarbiausia ligos priežastimi laikẻ kaltūną! Ši medicinos daktaro interpretacija yra suprantama ir galbūt netgi pateisinama: kaltūnas Vil- 
niaus krašte, kaip ir kituose Vakarų Europos miestuose, XIX a. pirmojoje pusejje vis dar buvo įvardijamas kaip savarankiška, sisteminè viso organizmo liga ir vienas iš nervų ligų etiologinių veiksnių [24].

Rudolfui Virchovui (Rudolf Virchow; 1821-1902) XIX a. antrojoje pusejje paskelbus, kad kiekviena nauja ląstelè atsiranda iš kitos ląstelès (omnis cellula e cellula), bei įtvirtinus ląstelinès patologijos teoriją, įsitvirtino solidizmo doktrina, o keturių organizmo skysčių doktrinos aukso amžius baigèsi [2]. Kita vertus, moderniais laikais humoralizmo teorija vėl atgimė imunologijos srityje (ląstelinio, humoralinio imuniteto sąvokos), todèl šiandien infekcinių, autoimuninių bei kitų ligų patogenezès suvokime yra svarbios abi teorijos.

\section{IŠVADA}

Solidizmo doktrina Vilniaus klinikose buvo pripažįstama ir šios sistemos principais (ligos priežasčių derètų ieškoti vidaus organuose, o ne organizmo skysčiuose) buvo remiamasi, atliekant autopsijas ir klinikinę nervų liga sirgusio ligonio diagnozę patvirtinant po mirties.

\section{Literatūra}

1. Porter R. The greatest benefit to mankind. A medical history of humanity from antiquity to the present. London: Fontana Press, 1999.

2. Magner LM. A history of medicine. Boca Raton: Taylor \& Francis Group, 2005.

3. Finger S. Origins of neuroscience. A history of explorations into brain functions. Oxford University Press, 1994.

4. Hull G. The influence of Herman Boerhaave. J R Soc Med 1997; 90(9): 512-4. https://doi.org/10.1177/ 014107689709000915

5. Ishizuka H. 'Fibre body': the concept of fibre in eighteenthcentury medicine, c. 1700-40. Med Hist 2012; 56(4): 562-84. https://doi.org/10.1017/mdh.2012.74

6. Schutta HS. Morgagni on apoplexy in De Sedibus: a historical perspective. J Hist Neurosci 2009; 18: 1-24. https://doi.org/10.1080/09647040701578219

7. Booth C. Herman Boerhaave and the British. Part 1: Boerhaave and the science of healing. J R Coll Physicians Lond 1989; 23(2): 125-9.

8. Chomel A. Elements of general pathology. Third edition, considerably enlarged. Translated from the French by F. E. Oliver, and W. W. Morland. Boston: William D. Ticknor and Company, 1848.

9. Herberski VV. Dissertatio inauguralis medico - practica de hydrope specus vertebralis. Vilnae: typis Iosephi Zawadzki Universitatis typographi, 1812.

10. Dyrwiański J. Dissertatio inauguralis historiam hydrophobiae exhibens. Vilnae: typis R. F. O. S. Basilii, 1815.

11. Godziemba A. Tentamen inaugurale diagnosim typhi et encephalitidis sistens. Vilnae: typis Dioecesanis, 1812.

12. Gutt F. Dissertatio inauguralis medico - practica analecta de morbis columnae vertebralis exhibens. Vilnae: typis Dioecesanis Congr. Missionis, 1823.

13. Meškauskas J. Lietuvos medicinos istorija. Chicago: Pasaulio lietuvių gydytojų sajunga, 1987.
14. Ragauskienė R. XVI a. pab. ATR valdovų gydytojas italas Mikalojus Bukcelè. Prieiga per internetą: http://m.ldkistorija.lt/index.php/istoriniai-faktai/xvi-a-pabatr-valdovu-gydytojas-italas-mikalojus-bukcele/1375

15. Simonii S. Commentariola medica et physica ad aliquot scripta. Vilnae: Impress per Iohannem Kartzanum, 1584.

16. Frank JP. Biography of Dr. Johann Peter Frank, imperial and royal court councillor, hospital director and professor of practical medicine at the University in Vienna, member of various learned societies, written by himself (iš vokiečių $\mathrm{k}$. vertė G. Rosen). J Hist Med Allied Sci 1948; 3(1): 11-46. https://doi.org/10.1093/jhmas/III.1.11

17. D’Angers CPO. Traité des maladies de la moelle epiniére. Paris: Méquignon-Marvis père et fils, 1837.

18. Catani M, Sandrone S. Brain renaissance from Vesalius to modern neuroscience. New York: Oxford University Press, 2015. https://doi.org/10.1093/med/9780199383832. 001.0001

19. Sniadecki J. Teorya jestestw organicznych. Tom I. W Warszawie: w Drukarni No 646 przy Nowolipiu, 1804.

20. Sniadeckis A. Organinių būtybių teorija. Vilnius: Vilniaus universiteto leidykla, 2018.

21. Libiete I. Imagination matters: a historical overview of the theory of maternal impressions. Abstracts of the 24th meeting of the International Society for the History of the Neurosciences. Vilnius: Vilniaus universiteto leidykla, 2019; 29.

22. Kaczkowski M. Dissertatio inauguralis medico - practica de hydrophobia. Vilnae: typis Dioecesanis, 1829.

23. Baehr M, Frotscher M. Duus' topical diagnosis in neurology. $4^{\text {th }}$ completely revised edition. Stuttgart, New York: Thieme, 2005.

24. Sakalauskaitė-Juodeikienė E, Jatužis D, Kaubrys S. Plica polonica: from national plague to death of the disease in the nineteenth-century Vilnius. Indian J Dermatol Venereol Leprol 2018; 84(4): 510-4. https://doi.org/10.4103/ ijdvl.IJDVL_673_17

\section{E. Sakalauskaitè-Juodeikienẻ}

\section{THE DOCTRINE OF SOLIDISM AND NEUROLOGY IN THE FIRST HALF OF THE 19TH CENTURY IN VILNIUS}

\section{Summary}

In the first half of the 18th century, European medical literature was pervaded with fibre-related terms such as "membranes", "web", "vibrating", "folding", "tone", "tension", etc. The doctrine of humoralism which attributed all diseases to imbalance of the four humours was gradually replaced by a new doctrine of solidism suggesting that fibres were the most important building units of the body. How was the doctrine of solidism received and how did it change the perception and diagnosis of nervous system diseases in the first half of the 19th century in Vilnius? After analysing several doctoral dissertations, written in Latin and defended at Imperial University of Vilnius, we came to the conclusion that the causes of nervous system diseases were mostly sought in the cerebrum and spinal cord, using autopsy findings as an essential part of the anatomo-clinical method, under the influence of the principles of the doctrine of solidism.

Keywords: solidism, autopsy, nervous system diseases, Vilnius university, Vilnius clinics.

Gauta:

Priimta spaudai:

20191222 